\title{
CONDIÇÕES DE ATENDIMENTO NA UNIDADE DE EMERGÊNCIA: UM ESTUDO QUALITATIVO COM FAMÍLIAS DE PACIENTES
}

\author{
CONDITIONS FOR CARE IN AN EMERGENCY ROOM: \\ A QUALITATIVE STUDY WITH FAMILIES OF PATIENTS \\ CONDICIONES DE ATENCIÓN EN LA UNIDAD DE EMERGENCIA: \\ UN ESTUDIO CUALITATIVO CON FAMILIARES DE PACIENTES
}

\author{
Leandro Barbosa de Pinho* \\ Luciane Prado Kantorski**
}

* Professor Assistente da Universidade Federal de Mato Grosso - UFMT. Mestre em Enfermagem pela UFSC. Doutorando em Enfermagem
Psiquiátrica pela EERP-USP. Apoio CNPq.
** Professora Adjunta da Faculdade de Enfermagem e Obstetrícia da Universidade Federal de Pelotas - UFPel. Doutora em Enfermagem. Apoio CNPq.

RESUMO. Este estudo pretende refletir acerca da opinião de familiares que vivenciam a internação de seu parente em uma unidade de emergência sobre as condições de atendimento. Trata-se de um estudo de grupo, qualitativo, realizado com familiares de três pacientes internados em uma unidade de emergência de uma cidade do Estado do Rio Grande do Sul, Brasil. Utilizou-se como técnica de coleta de dados a entrevista semi-estruturada e a observação participante. Os resultados apontam a evidência de sofrimento psíquico nas famílias, em função de haver falta de envolvimento emocional com seus parentes e com os trabalhadores da unidade, além das complicações psicossociais. De acordo com os relatos, pode-se inferir que parece haver uma fragmentação teórico-prática na profissão de enfermagem, quando os auxiliares e técnicos de enfermagem, que prestam cuidados diretos, são personagens que se relacionam com seus pacientes e familiares, enquanto os enfermeiros se dedicam à coordenação, supervisão e administração dos serviços de enfermagem, distanciando-se, mesmo que inconscientemente, dos sujeitos de seu cuidado. Acreditamos que esse estudo pode ser uma contribuição para repensar a prática de cuidados de enfermagem, especialmente nas unidades de urgência e emergência.

PALAVRAS-CHAVE: relações profissional-família; serviços médicos de emergência; saúde do adulto.

\begin{abstract}
We intend to present the opinions of families, who have a relative as an in-patient, concerning the conditions of attendance in a unit of the casualty department. It consisted on a study group of qualitative, descriptive and analytical character, developed with families of in-patients of the emergency unit of a casualty department unit from a city in the south of Rio Grande do Sul, Brazil. With the present study we verified that the families of in-patients at the emergency unit suffer psychologically in the face of the hospitalization and of the realization of so many obstacles. According to what the families said, we can infer the creation of a theoretical-practical fragmentation in the profession, as a function of the nursing auxiliaries and technicians, in their more direct care to patients, being the ones who most related themselves to the patients and their families. The nurses kept in charge of the coordination and superintendence of the auxiliaries and technicians' work and of the administration of the nursing services, being aloof, even though unconsciously, from the subjects of their care. We believe that this study brings a substantial contribution by allowing us to think over the nursing professional practice in Brazilian hospitals and, in our case, in the emergency units.
\end{abstract}

KEYWORDS: professional-family relations; emergency medical services; adult health.

RESUMEN. Este estudio pretende reflexionar acerca de la opinión de familiares que vivencian la internación de su pariente en una unidad de emergencia sobre las condiciones de atención. Se trata de un estudio de grupo, cualitativo, realizado con familiares de tres pacientes internados en una unidad de emergencia de una ciudad de la Provincia de Rio Grande do Sul, Brasil. Se utilizó la entrevista seme-estructurada y la observación participativa. Los resultados apuntan la evidencia del sufrimiento psíquico en las familias, mediante la falta del envolvimiento emocional y de las complicaciones psicosociales. De acuerdo con los relatos, se puede inferir que parece haber una fragmentación teórico-práctica en la profesión de enfermería, pues los auxiliares y técnicos de enfermería, en sus cuidados directos a los pacientes, son los que se relacionan con estos y sus familiares. Todavía los enfermeros se quedan a cargo de la coordinación, supervisión y administración de los servicios de enfermería, distanciándose, mismo que inconscientemente, de los sujetos de su cuidado. Acreditamos que este estudio puede ser una contribución al repensar de la práctica de enfermería, y, en nuestro caso, en las unidades de urgencia.

PALABRAS-CLAVE: relaciones profesional-familia; servicios médicos de urgencia; salud del adulto.

Recebido em: 31/05/2006

Aceito em: $\quad$ 03/07/2006
Leandro Barbosa de Pinho

Av. Antonio Joaquim, 365

78600-000 - Barra do Garças/MT

Telefone: 066-81237109 - E-mail: Lbpinho@uol.com.br 


\section{INTRODUÇÃO}

Lidar com seres humanos não é tarefa expedita. A complexidade humana nos confirma isso. Em muitos momentos, somos atingidos por uma felicidade ou alegria tamanha, como quando nos apaixonamos por alguém. Contudo também vivenciamos situações tristes, em que muitos de nossos desejos e aspirações são interrompidos com momentos inusitados, não desejados, exigindo readaptações e redimensionamentos de nossas atividades cotidianas.

O processo de adoecimento de uma pessoa, por exemplo, podemos considerar como um desses momentos difíceis, que exige de toda a estrutura de uma família certa readaptação, alterando perspectivas futuras. No entanto, quando falamos de adoecimento com a necessidade de hospitalização, outros fatores participam dessa reorganização familiar, como as condições físico-emocionais do paciente e a disponibilidade dos profissionais de saúde.

Na idade média, o hospital constituía em uma instituição de caridade, que prestava cuidado a pobres e moribundos, indivíduos esses marginalizados pela sociedade da época. O cuidado aos pacientes era prestado por irmãs de caridade, com interesses apenas religiosos: a cada paciente cuidado, a redenção e o perdão dos pecados se tornavam mais próximos. Contudo, com o advento do capitalismo e a captura dos processos de trabalho pelos hospitais, a instituição passou a cuidar de doentes com fins curativos ${ }^{1}$.

Na Guerra da Criméia, houve aumento da peste, da contaminação do solo, da água e disseminação de doenças e condições insalubres de vida, principalmente nos hospitais militares para os quais os soldados feridos eram levados. Florence Nightingale, precursora da enfermagem moderna no mundo, conscientizava-se de que era necessário um treinamento da equipe de enfermeiras para fazer face a essas condições. Em função de seu referencial disciplinado, que preconizava certa sistematização da assistência, logrou uma redução das taxas de mortalidade de soldados internados em um hospital militar de $40 \%$ para $2 \%$. Florence também acreditava que o cuidado, além de ser disciplinado, deveria ser direcionado ao conforto do paciente dentro do hospital, priorizando-se as boas condições do ambiente, como estimuladores do seu bem-estar e, conseqüentemente, de sua reabilitação ${ }^{2}$.

O hospital é secular, sendo um recurso importante para a recuperação da saúde humana. Porém, como qualquer outro serviço de saúde, também apresenta suas limitações e potencialidades ${ }^{~}{ }^{\text {. No }}$ Brasil, a assistência hospitalar, principalmente na área de urgência e emergência, sofre com a falta de recursos humanos, materiais e financeiros adequados, além da superlotação e da sobrecarga de trabalho dos profissionais.

Alguns estudos ${ }^{3 ; 6}$ mostram que as instituições hospitalares ainda trabalham sob o ritmo da medicina curativa, em que as técnicas e tecnologias no cuidado do corpo perduram. Ainda é incipiente o atendimento das demandas psicossociais de famílias e de pacientes durante a internação. E quando falamos do atendimento de emergência em uma unidade de Pronto-Socorro, acreditamos que se evidenciam limitações ainda mais expressivas.

A família que vivencia uma internação em ProntoSocorro convive diariamente com muitas contradições. Quando procura atendimento na unidade, espera resolutividade, a qual, de certa forma, encontra, mas se depara com situação precária de atendimento, com a deficiência de recursos humanos, materiais, infra-estrutura, além da superlotação. Além disso, deve encarar o pouco envolvimento da equipe de saúde, o distanciamento, a impaciência em algumas situações e as discussões interprofissionais que algumas vezes presenciam.

Este estudo trata de um recorte da monografia de conclusão da Graduação em Enfermagem de um dos autores, que teve por objetivo conhecer o contexto psicossocial das famílias que vivenciam a internação de um parente em uma unidade de emergência.

Constatou-se que as dificuldades enfrentadas no âmbito psíquico, como, por exemplo, a fragilidade 
emocional, o medo, a estranheza e a impotência diante da situação são relevantes para se discutir a problemática do cuidado de enfermagem prestado nessa unidade. A unidade de emergência, para a família, configura-se como fonte de inquietações e insegurança emocional que, em função do aparecimento desses sentimentos, desestruturam a dinâmica dos familiares. Nesse sentido, averiguouse que o cuidado humanizado na unidade ainda é elementar, pouco qualificado em termos de atenção psicossocial, porque os profissionais de saúde não valorizam, como parte do ambiente terapêutico, as inseguranças, as dúvidas, as carências, as perspectivas e, principalmente, as relações sociais de seus pacientes ${ }^{7}$.

É diante dessas discussões que pretendemos apresentar a opinião de famílias que vivenciam a internação de um familiar acerca das condições de atendimento em uma unidade de emergência de um Pronto-Socorro.

\section{METODOLOGIA}

Tratou-se de um estudo de grupo, de caráter qualitativo, descritivo e analítico, desenvolvido com familiares de um paciente internado na unidade de emergência de um pronto-socorro, localizado em cidade do sul do Estado do Rio Grande do Sul, Brasil. Propusemos descrever as inquietações dos familiares, suas dúvidas, desentendimentos, opiniões e inconformidades, fazendo interpretação dos dados obtidos à luz da bibliografia disponível. Para isso encaminhamos um documento, anexado à proposta do trabalho, para o comitê de ética em pesquisa da instituição e recebemos parecer favorável ao desenvolvimento do estudo.

Por descrever as particularidades e subjetividades de um fenômeno, a pesquisa qualitativa vem sendo considerada como o tipo de investigação mais apropriado às ciências humanas e sociais. A enfermagem, por ser de uma linha mais humanística, adaptou-se a essa nova forma de pensar e tem-se aperfeiçoado como profissão, ao evidenciar particularidades e subjetividades do indivíduo sob seus cuidados $8 ; 9$.
Qualquer realidade é circular, ou seja, está em contínuo processo de adaptação/re-adaptação, sofrendo mudanças, transformações ao longo do tempo. Um fenômeno intrínseco a essa realidade, da mesma forma, também é influenciado, adaptandose, movimentando-se, transformando-se. Sendo o homem um sujeito dessa realidade e em inter-relação direta com esta, é possível entender que ele se torna uma complexidade crescente que carece de olhar diferenciado. A pesquisa qualitativa ajuda a interpretar essa situação, levando em conta o significado, a expressão humana, a sua vida social, a sua multidimensionalidade ${ }^{10}$.

A família e o paciente que presenciam a internação em um serviço de emergência se vêem diante de um ambiente que Ihes possibilita/ impossibilita expressar seus significados e suas solicitações. Sendo sujeitos únicos em sua singularidade que vivenciam a rotina de um espaço social contraditório, é compreensível que surjam inquietações, inconformidades, dúvidas e opiniões diante das condições de atendimento. Entendemos, nesse sentido, que a pesquisa qualitativa poderá ajudar-nos na interpretação desse contexto.

Foram estudados todos os membros da família de 3 pacientes internados na respectiva unidade de emergência, que foram escolhidos segundo critérios previamente estabelecidos, como ter laço consangüíneo de no máximo segundo grau com o paciente, participar freqüentemente das visitas na unidade de emergência, dispor-se a participar do estudo e permitir a divulgação dos dados.

Cada família foi identificada com a letra $F$ seguida do número que corresponde à ordem em que apareceu no estudo (F1, F2 ou F3). Os pesquisadores permitiram que os investigados escolhessem um nome fictício para a participação no estudo, a fim de preservar suas identificações pessoais. Para fins de sistematização e melhor compreensão das relações familiares, optamos por identificar a família na seguinte ordem: Nome fictício do familiar - número correspondente da família na entrevista (F1, F2 ou F3) - grau de familiaridade com o paciente. Exemplo: Alice - F2 - Neta. 
Os dados que subsidiaram a construção deste estudo partiram da análise de entrevistas semiestruturadas, aplicadas às famílias. As entrevistas geraram dados significativos que foram submetidos à análise de conteúdo. Procuramos identificar "categorias nativas" emergidas da transcrição dos textos gerados pelas entrevistas. Através da releitura desse material, buscamos todos os elementos comuns a todas as entrevistas, visando definir as categorias e suas inter-relações, para que, finalmente, pudéssemos apontar o que de mais significativo foi dito pelos nossos informantes. Os principais eixos de discussão encontrados foram: a família e suas inquietações na unidade de Pronto-Socorro e o fazer da enfermagem na unidade de emergência; uma análise sob a ótica das famílias. Passaremos a discutir cada uma delas a seguir.

\section{RESULTADOS}

\section{A FAMÍLIA E SUAS INQUIETAÇÕES NA UNIDADE DE PRONTO-SOCORRO}

Em 2002, o Ministério da Saúde, reconhecendo a relevância do setor de urgências e emergências na saúde pública e admitindo a necessidade de uma redefinição de sua política, emitiu a portaria 2048/ 2002, que dispõe sobre a regulamentação técnica dos sistemas estaduais de urgência e emergência. Nela, reconhece-se o aumento da demanda de atendimento, a insuficiente estruturação de uma rede assistencial e a grande distância entre os municípios, prejudicando os primeiros atendimentos; resolveu-se criar os chamados Sistemas Estaduais de Urgência e Emergência, contribuindo para a regionalização da assistência, tão preconizada pela Norma Operacional Básica (NOB) 01/2002 do Sistema Único de Saúde.

Essa portaria estabelece parâmetros de criação da rede assistencial de urgências e emergências, estimulando a tomada de decisões em nível municipal e estadual. Garante a implantação de uma rede de assistência pré-hospitalar, a qualificação permanente e contínua dos profissionais de urgência e emergência e reforça a importância do acolhimento na atenção básica para evitar o deslocamento desnecessário dos pacientes de sua área de origem para tratamento no Pronto-Socorro. Esta realidade ocasiona uma descontinuidade do atendimento primário e a violação do princípio de hierarquização da assistência em saúde.

Assim, ficam responsáveis os Estados e os Municípios pela garantia da correta capacitação dos recursos humanos, pelo acolhimento dos casos agudos e pela disposição adequada do espaço físico de atendimento.

O Ministério da Saúde considera, em sua portaria, o nível de atendimento das urgências e emergências como sendo de alta complexidade. De fato, quando entendemos "alta complexidade", imediatamente remetemo-nos ao suporte tecnológico, com equipamentos modernos, pessoal capacitado e bem remunerado, como também serviços estruturados e que adequadamente funcionem.

Entretanto, ao falarmos de Sistema Único de Saúde, ainda podemos observar limitações, que vão desde os recursos humanos e materiais, até a administração dos serviços. Esse contexto, vivenciado no dia-a-dia pelos profissionais que no Pronto-Socorro trabalham, também é notado pela família. Ao mesmo tempo que os familiares sentem as dificuldades e as impossibilidades do sistema público, também comentam as necessidades de se possuir um sistema privado de atendimento. Os seguintes relatos expressam essa condição:

Eu acho que pelo menos o Pronto-Socorro deveria ser uma coisa super equipada, sabe? Porque é o último recurso que o pobre tem... As pessoas no chão, isso ai é um absurdo, então era pra ter mais hospital, o prontosocorro era pra ser pelo menos uma coisa boa. Mas o que se vai fazer? A vida é isso, a gente tem que aceitar, a gente não tem condições de ter um plano, não pode pagar, o que a gente vai fazer? (Brenda - F1 - Filha).

Eu fiquei muito chateada... eu não tenho dinheiro pra eles ter um plano de saúde (Patrícia - F1 - Esposa).

Ainda tava comentando ontem à noite que as pessoas que deveriam ser mais bem pagas pelo presidente 
eram os médicos e os enfermeiros, todos da equipe médica, era uma equipe que deveria ser muito bem respeitada... (Talia - F3 - Mãe).

Eu pelo telefone escutei a mãe falando pra mim que ela tava no CTI e eu me dei conta que era público... Eu pensei: Meu Deus, que me espera?... quando a gente chegou e viu como é isso aqui, aquele entra e sai de doente, aquele horror, porque pra mim foi um horror ficar sentada ali na porta... ficar horas lá sentada sem saber de nada, e aquele entra e sai de gente doente, quer dizer, se acabando ali na frente... (Alice - F2 - Neta).

Fico me questionando se houvesse situação financeira de estar noutro lugar se seria diferente, se a gente não ficaria melhor, se ela estaria sendo tratada diferente... aquela posição ali dentro, num lugar público, se é o mesmo de lugar particular, eu acho que a gente sabe que seria diferente, a gente estaria dentro de um quarto bem confortável, com todo conforto... a gente nunca está preparado pra isso ai, a verdade é essa, a gente não se prepara, a vida pára, vai adoecer, vai pro hospital, a gente nunca pensa num plano de saúde. Deixa essas coisas sempre em segundo plano e só na hora da necessidade que a gente percebe. Esse é o questionamento que a gente fica, dentro desse quadro todo... lugar público e privado, qual é a diferença? (Nahir - F2 - Filha).

A realidade citada pelos entrevistados nos possibilita pensar que a prestação de um atendimento de qualidade está relacionada à possibilidade de usufruir de um plano de saúde supletiva. Como, para as famílias, o plano de saúde é oneroso, estando acessível apenas a uma parcela pequena da população, elas acabam recorrendo ao atendimento na rede pública de saúde. Nesse sentido, o sofrimento, já agravado pelo problema de saúde de seu parente, parece ser potenciado em face das contradições que emergem no imaginário familial, quando as reais necessidades da família de ter um serviço de saúde de qualidade entram em conflito com a realidade assistencial pouco resolutiva, em termos de cuidado e acolhimento das suas demandas psicoemocionais.

O Pronto-Socorro é um local de atendimento para situações com risco de vida. A resolutividade faz com que o serviço seja escolhido como primeira opção, quando ocorre algum problema de saúde na família, seja ele de urgência ou emergência. Contudo quando os familiares chegam ao serviço, procurando atendimento, chocam-se ao vivenciarem tantas limitações e contradições.

A unidade de emergência suscita, na família e no paciente, uma complexa rede de determinantes psicossociais, em função das limitações que a unidade impõe. Nesse sentido, há a necessidade da presença do profissional enfermeiro como prestador de apoio e segurança a essas pessoas. Contudo o ambiente, por passar uma imagem de agressividade, muitas vezes se encarrega de contrariar essa necessidade ${ }^{11}$.

Em um estudo ${ }^{12}$, foram levantadas as condições de atendimento em um serviço de emergência em um hospital do Rio de Janeiro, constatando-se que aqueles casos considerados crônicos ou sem possibilidade de recuperação contribuíam, em grande parte, para a desorganização da unidade, tornando o atendimento na unidade de emergência tumultuado, impróprio e sem qualidade. Esse contexto imediatamente é recordado pela família, contribuindo para o aumento do desespero, da insegurança e do sofrimento psíquico.

Outros fatores levantados e que influenciam diretamente a prestação de cuidados na unidade de emergência, dizem respeito à desorganização dos quadros funcionais (médicos, enfermeiros e auxiliares/ técnicos de enfermagem), às baixas remunerações, ao mau aproveitamento de macas e leitos e ao limitado treinamento da equipe através da educação continuada. Por isso entende-se que as unidades de emergência se vêm constituindo num ambiente progressivamente degradante, o que é lamentável, considerando a complexidade do serviço e sua importância dentro de um contexto social de atendimento à saúde ${ }^{12}$.

De fato, os autores têm razão em apontar a problemática do atendimento nas unidades de emergência. Caso fizéssemos um levantamento no setor, evidenciaríamos que parcela relevante dos pacientes poderia ser tratada em unidades básicas 
de saúde. Por não haver condições suficientes para o acompanhamento nessas unidades, acabam Iotando o Pronto-Socorro. Nesse sentido, cria-se um obstáculo ao trabalho com pacientes e familiares. Assim, o Pronto-Socorro, que deveria, teoricamente, ser o local destinado ao atendimento das urgências e emergências, na prática não o é, já que não caminha para uma tentativa de redefinição social de suas finalidades.

Nesse contexto, a desorganização da unidade e as limitações de atendimento se tornam fontes geradoras de sofrimento psíquico na família, como se pode evidenciar no relato de Alice anteriormente. Devemos, enquanto profissionais de saúde, dedicar atenção especial a essa situação, mobilizando-nos por condições dignas de atendimento, reivindicando necessidades imediatas e problematizando esse contexto junto à administração pública.

\section{O FAZER DA ENFERMAGEM NA UNIDADE DE EMERGÊNCIA: UMA ANÁLISE SOB A ÓTICA DAS FAMÍLIAS}

O relacionamento humano é tão complexo quanto o próprio ser humano. Da mesma forma, as reações humanas diante de determinadas ocasiões também diferem. Para algumas pessoas, lidar com as perdas, a dor e o sofrimento causados pela internação é possível com a união dos laços afetivos entre os familiares. Para outras, a situação se torna difícil, exigindo compreensão e entendimento por parte de quem cuida no ambiente hospitalar. Nesse caso, a atenção, o toque, o olhar direcionado, a escuta atenta e interessada, por mais breve que seja, acalenta um rosto marcado pela tristeza, pela ausência de apoio, pelo desespero diante do risco de vida que a unidade de emergência impõe.

Brenda, Patrícia, Eliete, Alice e Talia, em suas oportunidades no acompanhamento dos exames de seus parentes, comentam a disponibilidade da enfermagem na prestação dos cuidados aos seus familiares internados:
Eu fui levar ele no Raio $X$, até o enfermeiro que levou é um rapaz muito bom, ele ficava na volta dele, conversou direitinho comigo, disse que ia falar com a doutora pra depois conversar comigo... bem legal ele, sabe? Eu ajudei ele a segurar o braço dele pra ficar retinho... (Brenda - F1 - Filha).

Também me trataram bem... os enfermeiros sempre foram muito bons pra mim... (Patrícia - F1 - Esposa).

Aqui na emergência mesmo a enfermeira chamou às 04 horas da madrugada pra ir lá dentro dar uma olhadinha, molhar os lábios dele com gaze, não sei se é o tratamento dela... O atendimento foi muito carinhoso da enfermagem (Eliete - F3 - Tia).

No corredor teve uma moça que atendeu muito bem, ela é muito querida... (Alice - F2 - Neta).

A equipe da enfermagem, da recepção, da limpeza, todo mundo... tudo que a gente pergunta, quer saber, eu pergunto pra elas se pode pegar água, elas respondem que sim, pode pegar um pouquinho, molha a gaze ali e dá pra ele... o soro terminou, eu avisei, demoraram, mas vieram, lá no $R X$ a enfermeira e o enfermeiro que levaram ele foram muito atenciosos... (Talia - F3 - Mãe).

Percebemos nas falas destacadas que o relacionamento interpessoal de auxiliares de enfermagem com as familiares (embora caracterizados como enfermeiros pelas participantes) evidencia uma preocupação pessoal dos profissionais com 0 sofrimento humano e com a dor naquele momento de hospitalização. Embora em sua formação profissional sejam priorizados conteúdos de ordem técnica e pouco centrada nas relações interpessoais, sua presença constante na hora dos exames e a atenção dispensada resgataram a profissão de enfermagem como o saber-fazer humanizado, preocupado com o conforto físico e emocional do ser humano em sua inteireza, aliviando as condições de sofrimento psíquico impostas pela internação, mediando as relações interprofissionais no âmbito hospitalar, enfim promovendo saúde mental.

O ser humano deve ser íntegro o suficiente para que possa lidar com seus sentimentos negativos, problemas, desagrados, sofrimentos e vicissitudes. 
Deve construir sua trajetória resiliente, lutar por condições satisfatórias de vida, de bem-estar, tendo a família incisivamente ao seu lado, nos diversos níveis do ciclo vital. Deve receber ajuda terapêutica quando necessário, principalmente nos momentos em que não consegue lidar com essas adversidades ${ }^{13}$.

O relacionamento interpessoal torna-se instrumento de ajuda nesses momentos. Possibilita o entendimento do mundo interno do paciente, de suas demandas psicossociais, de suas necessidades individuais. Através do processo terapêutico, o profissional de enfermagem, o paciente e os membros familiares se reconhecem como pessoas importantes no mundo, que têm uma história de vida, relações sociais, incompatibilidades e limitações. A relação com o outro parte de um processo empático, de um espaço de reflexão, levando ao reconhecimento mútuo, às transformações intra e interpessoais, em que todos os participantes, num compasso dialético, compartilham de suas trajetórias para enfrentarem os conflitos e intempéries que, nesse caso, a hospitalização na emergência Ihes impõe.

Somente nos conhecemos e reconhecemos o outro enquanto indivíduos participantes de uma experiência, quando reagimos em nossa totalidade de ser humano. Em sua construção dialógica do "Eu" e do "Tu", o autor compreende o encontro entre duas pessoas como fundamento de suas existências, como forma de se construir uma ontologia da relação inter-humana. Numa relação entre o "Eu" e o "Tu", os seres humanos em contato presenciam uma reciprocidade, que são atos humanos e exclusivamente humanos ${ }^{14}$.

Consideramos o relacionamento interpessoal como processo de experiência recíproca, em que se cresce pessoal e profissionalmente, quando em contato com o outro. Ademais, é extremamente intersubjetivo; as crenças, os valores, a disponibilidade pessoal e as visões de mundo também entrarão como instrumentos no processo terapêutico. No entanto a realidade do processo de cuidar centrado na relação interpessoal ainda é incipiente, sendo notada por alguns familiares durante os cuidados aos pacientes. As seguintes falas expressam essa afirmação:
Ai eu cheguei... deixaram eu entrar, mas ninguém me avisava nada... "Ah! depois quando der a doutora vai falar contigo" e eu esperei um monte pra saber até porque que ele tinha vindo. Nessa hora a pessoa fica meio nervosa... E eu cheguei... só fui saber depois porque que ele tinha baixado quando o doutor me disse (Brenda - F1 - Filha).

Vou dizer que quando eu entrei vi todo mundo sentado lá num canto conversando e rindo e a minha vó ali, daquele jeito e eu sem saber de nada... Eu acho que podia ter mais informação, podiam dar mais atenção, sabe? Eu não esqueci do rosto do enfermeiro que perguntou o que que eu era dela. Por quê? Porque ele parou pra perguntar. Ele se importou de alguma forma, não sei por que, mas se importou... Falta muito o lado humano da coisa... (Alice - F2 - Neta).

Não tem comunicação realmente... a comunicação existe somente quando é solicitada... Quando foi solicitado eu fui atendida, mas tu precisas solicitar. Ninguém chegou pra saber "está tudo em ordem? Não estás precisando de nada? Como é que tá?" Não, simplesmente passa pra lá, passa pra cá. (Nahir - F2 - Filha).

Eu também acho que sem conversa tu ficas imaginando coisas na tua cabeça e isso ai causa pânico... a gente sabe que aquilo ali é uma emergência, que vocês estão ali pra atender os pacientes dali e os que estão pra chegar. Não tem como a gente ta incomodado eles, querendo saber informação, né? (Eliete - F3 - Tia).

Se tivesse uma pessoa pra informar a gente e tranqüilizar seria maravilhoso porque a gente sabe que nessa situação qualquer palavra por mínimo que seja pra gente é um conforto... Porque ficar imaginando coisas deixa a gente atacado, mexe com os nervos da gente... Essa falta de informação que pra vocês parece uma coisa normal porque vocês estão acostumados com aquilo, pra gente que não entende nada qualquer coisinha... a gente já se apavora (Talia - F3 - Mãe).

Então eu penso assim, sério, eles querem que morra mesmo pra ser menos um... não estão nem ai, ainda ficam rindo um pro outro, e eu choro quando eu chego em casa... mas eu me agarro com Deus, porque ele sabe o que faz (Patrícia - F1 - Esposa).

Os relatos destacados retratam a ausência de envolvimento afetivo de alguns profissionais de 
enfermagem. Em suas oportunidades de visita aos seus familiares na emergência, os entrevistados constataram que ainda é precário o envolvimento emocional da equipe de saúde com os familiares. Para eles, o lado humano do atendimento, com vistas à minimização do sofrimento psíquico, está no olhar, na palavra adequada, na escuta, no abraço zeloso, sendo mais importante que a priorização do conhecimento técnico-científico que fundamenta a prática rotinizada e compartimentalizada nessas unidades.

As carências de relacionamento interpessoal existentes na unidade de emergência são comuns na realidade brasileira dos serviços de saúde pública, sendo vivenciadas, principalmente, por aqueles que procuram o atendimento no caso de necessidade imediata, como a família. De fato, um dos autores também pôde comprovar essa realidade durante o estágio curricular de sua formação profissional. Notou que a maioria dos profissionais de nível superior incluindo enfermeiros, dotados de saberes científicos multidisciplinares, voltados, também, à compreensão das necessidades psicossociais de seus pacientes) são os que menos se relacionam com os familiares durante a visita, momento mais apropriado para o estabelecimento de uma experiência terapêutica. $\mathrm{O}$ enfermeiro ficava ocupado da supervisão do trabalho dos auxiliares e técnicos. Já os auxiliares e os técnicos de enfermagem (dotados de saberes tecnológicos, habilidades manuais) relacionavam-se mais com pacientes e familiares, acolhendo-os e estabelecendo vínculos afetivo-emocionais.

A profissão de enfermagem no Brasil seguiu os moldes do modelo nightingaleano, que construiu um saber pautado nas técnicas, nas rotinas e na seqüência de procedimentos, sob subordinação aos conhecimentos médicos e sua supervisão imediata. Com o cuidado aperfeiçoado, a enfermeira passou a se responsabilizar pela coordenação e supervisão das práticas de enfermagem, enquanto os auxiliares e técnicos ficaram a cargo das tarefas com os pacientes ${ }^{15}$.

A enfermeira da época deveria ser rápida e eficiente, ou seja, exclusivamente prática e técnica.
As tarefas eram distribuídas de acordo com a sua inteligência e competência, cabendo ao auxiliar ou técnico de enfermagem a sua execução. Somente por volta de 1950, emerge a necessidade de se eliminar o empirismo das técnicas e estabelecer, permanentemente, os princípios científicos da prática de enfermagem (leis, doutrinas, verdades) que regem o cuidado humano ${ }^{1}$.

Posteriormente, a enfermagem sentiu necessidade de instituir um saber científico independente da prática médica, procurando instrumentos em outras áreas do conhecimento, como a filosofia, a sociologia, a antropologia e a psicologia como complementação para a prestação de seus cuidados ${ }^{15}$.

Entendemos que o saber de enfermagem é histórico, em constante atualização. Atualmente, com as contribuições da filosofia, da psicologia e da sociologia, a enfermagem constrói e reconstrói conhecimentos do ser humano, enxergando-o como sujeito social, histórico e pessoa, em constante interação consigo e com os outros, que possui necessidades específicas, relações sociais, sendo singular em toda sua história de vida.

Todavia a cientificidade da prática profissional que criou o saber estruturado e fundamentado no tecnicismo, na administração e coordenação de equipes ainda é hegemônica em nosso meio. Esse eixo de trabalho não deveria implicar a negação/ ausência do profissional enfermeiro como promotor de saúde mental de pacientes e familiares através do uso do relacionamento terapêutico, porém o predomínio da burocratização da assistência e da prestação de cuidados centrada no modelo biomédico confirma nossas afirmações.

Entendemos que a ausência de uma prática elencada na relação humana por parte de alguns enfermeiros pode gerar mais uma fragmentação teóricoprática na profissão, além de uma perda de identidade profissional. O enfermeiro acaba perdendo espaço para o desenvolvimento de novas e poderosas tecnologias assistenciais, como o relacionamento terapêutico, quando as necessidades psicossociais do paciente, incluindo as de sua família, são confiadas (mesmo 
que inconscientemente) a auxiliares e técnicos de enfermagem que, por si sós, já desenvolvem o cuidado ao indivíduo numa perspectiva rotineirizada, compartimentalizada e retificada.

Embora não se justifique, salientamos que muitos dos profissionais são sobrecarregados de atividades, tendo que atender as mais diversas necessidades dos pacientes que procuram o serviço. A superlotação das unidades também se transforma em fator limitante do relacionamento terapêutico como prestação de cuidado humanizado, tendo a equipe que se dedicar ao cuidado centrado no corpo do paciente e em suas necessidades biológicas imediatas, muitas vezes sob o constante risco de vida iminente.

Percebemos que a unidade de emergência ainda possibilita à enfermagem uma interlocução de saberes e práticas teórico-tecnológicas de grande expressividade, abrangendo a complexidade da dimensão humana. $\mathrm{O}$ contato com os mais diversos profissionais da área da saúde, como psicólogos, médicos e assistentes sociais permitiria a exploração de casos clínicos, a elaboração de planos terapêuticos sistematizados e o trabalho visando à promoção da saúde física e psíquica desses pacientes e familiares atendidos.

Compreendemos que essa realidade necessita ser repensada pelos educadores das escolas de enfermagem e pelos próprios profissionais em suas atividades assistenciais. Devemos estar cientes de que o relacionamento terapêutico é instrumento essencial no cuidado a pacientes e familiares que apresentam importantes demandas psicossociais em função da hospitalização. Assim nos aproximamos das práticas humanizadas, conhecendo os sujeitos dos nossos cuidados, reconhecendo-nos também com a experiência, crescendo pessoal e profissionalmente, como também resgatando os princípios de uma prática assistencial integralizada e globalizante.

\section{CONSIDERAÇÕES FINAIS}

Com o presente estudo verificamos que as famílias de pacientes internados na unidade de emergência sofrem psiquicamente diante da hospitalização e da constatação de tantos obstáculos. Muitas verbalizaram suas indignações, seus desabafos, suas críticas, suas inseguranças e seus medos em face do desligamento temporário com o familiar. Seus sentimentos negativos demonstraram o contexto psicossocial perante a situação clínica e perante ao atendimento prestado pela equipe de saúde da unidade ao paciente, atendimento amenizados quando existia envolvimento emocional com os funcionários da unidade, ou exacerbado diante da ausência de relacionamento de tais profissionais.

De acordo com os relatos dos familiares, podemos inferir que se cria uma fragmentação teóricoprática na profissão, em função de que os auxiliares e técnicos de enfermagem, em seus cuidados mais diretos com os pacientes, eram os que mais se relacionavam com eles e seus familiares. Pelo contrário, os enfermeiros ficavam encarregados da coordenação, da supervisão dos auxiliares e técnicos e da administração dos serviços de enfermagem, distanciando-se, mesmo que inconscientemente, dos sujeitos de seus cuidados.

Entendemos que o enfermeiro, nessa situação, acaba reproduzindo o modelo assistencial biomédico, tecnicista, centrado no corpo da pessoa, em que as necessidades psicossociais dos indivíduos são postas em segundo plano durante a prestação dos cuidados de enfermagem. Isso gera, além de uma fragmentação teórico-prática, uma contradição teóricoprática na profissão, em função de que a humanização no contexto hospitalar é preconizada e defendida pelos profissionais, mas que, na prática, pouco representa e pouco se realiza.

\section{REFERÊNCIAS}

1 Almeida MCP, Rocha JSY. O saber de enfermagem e sua dimensão prática. 2. ed. São Paulo: Cortez; 1989.

2 Paixão W. História da Enfermagem. 5. ed. Rio de Janeiro: Júlio Reis - Livraria; 1979.

3 Pitta AMF. Hospital: dor e morte como ofício. 2. ed. São Paulo: Hucitec; 1996. 
4 Franco MC, Jorge MSB. Sofrimento do familiar frente à hospitalização. In: Elsen I, Marcon SS, Silva MRS., organizadores. O viver em família e sua interface com a saúde e a doença. Maringá: Eduem; 2002. p.181-98.

5 Pessini L. Humanização da dor e sofrimento humanos na área da saúde. In: Pessini L, Bertachini L., organizadores. Humanização e cuidados paliativos. 2. ed. São Paulo: Edições Loyola; 2004. p.11-30.

6 Henckemaier L. Dificuldades ao cuidar da família no hospital. In: Elsen I, Marcon SS, Silva MRS., organizadores. O viver em família e sua interface com a saúde e a doença. Maringá: Eduem; 2002. p. 403-19.

7 Pinho LB. O contexto psicossocial da família do paciente internado na unidade de emergência. [monografia]. Pelotas (RS): Faculdade de Enfermagem e Obstetrícia da Universidade Federal de Pelotas; 2003.

8 Morse JM. Qualitative nursing research: a free-for-all? USA: Sage; 1991. p.14-24.
9 Streubert HJ. Philosophical dimensions of qualitative research. In: Streubert HJ, Carpenter DR., organizadores. Qualitative research in nursing - advancing the humanistic imperative. USA: J.B. Lippincott Company; 1992. p.1-14.

10 Chizzotti A. Pesquisa em ciências humanas e sociais. São Paulo: Cortez; 1991.

11 Nazário NO. Fragmentos de uma construção do assistir em situações de emergência/urgência. Florianópolis: Insular; 1999.

12 Soares E, Zysko L, Regazzi ICR, Silva LR. Diagnóstico das condições de atendimento de emergência em pronto-socorro: estudo prospectivo. Cogitare Enferm 1996; 1(1):73-7.

13 Prado LC. O ser terapeuta. Porto Alegre: UFRGS; 2002.

14 Buber M. Eu e tu. São Paulo: Moraes; 1974.

15 Kohlrausch E. O modelo assistencial clínico e algumas possibilidades de fazer diferente. Rev Gaúch Enferm 1999; 20(n. esp): 70-85. 